\title{
22. Conflictual and consensual disagreement
}

\author{
Brook Bolander and Miriam A. Locher
}

\begin{abstract}
This chapter explores a series of foci which have emerged in the study of disagreement in social media, notably in Web 2.0 environments. These include comparisons between disagreement online and offline; the role played by social and medium factors for the linguistic realisation and emergent meanings of disagreement; the recent upsurge in work on sociable disagreement and play; a focus on disagreement, language and gender; the exploration of disagreement in connection with polylogues and participation frameworks; increased interest in disagreement in educational contexts; and a progressive move to include data from language varieties other than English. To account for the fact that disagreement is a move which can have various manifestations and meanings, we also include discussion of "conflictual disagreement" and "consensual disagreement". In the course of the chapter, we further highlight the close relationship between changes in the study of disagreement online and changes in the study of language use online more generally; and we address contemporary research on the challenge of context and the indexing of emotion as pertinent for the study of disagreement online.
\end{abstract}

\section{Introduction}

This chapter focuses on conflictual and consensual disagreement in social media. Social media is thereby broadly conceived of as "(the totality of) digitally mediated and Internet-based platforms which are interactively used (by individual and collective participants) to exchange, share and edit self- and other-generated textual and audio-visual messages" (Hoffmann, Ch. 1, this volume). In this entry, disagreement is conceptualised as a 'discourse move' (Locher 2006) or contribution used to express opposition with a position, stance, or view taken by another party/ ies and/or source (cf. e.g., Locher 2004; Baym 1996; Bolander 2012, 2013). In exploring disagreement, we are particularly interested in its linguistic and semiotic performance (achievement and effects), and in the multitude of social and medium factors (Herring 2007) which influence its enactment online.

The beginning of research on disagreement online can be traced back to the mid 1980s (cf. e.g., Sproull and Kiesler 1986), with systematic, empirical research on disagreement emerging from the mid 1990s onwards (Baym 1996). Much has changed during this time, with technological advances concurring with changes in epistemology and approach. The shift from Web 1.0 to Web 2.0 has led to the 
emergence of new environments, modes and interactional affordances which offer increased possibilities for participation. With respect to approach and epistemology, we find a progressive move away from a view of disagreement as disruptive, to one which acknowledges the influence of multiple social and medium factors on issues of performance and perception. In other words, there is a shift towards a more varied and differentiated understanding of the functions of and different types of disagreement.

We begin our chapter by conceptualising disagreement against the backdrop of changes in technology and epistemology (Section 2), before reviewing key literature on conflictual and consensual disagreement (Section 3). Subsequently, we tackle two issues we view as pertinent to contemporary research on disagreement (Section 4): the challenge of context and the indexing of emotion. Finally, we provide an overview of key points and arguments, and an outlook to future research (Section 5).

\section{Disagreement: Conceptualisation and development from Web 1.0 to Web 2.0}

In the first special issue to deal with disagreement offline and online, Angouri and Locher (2012: 1551) argue for an approach which acknowledges four key factors: 1) "expressing opposing views is an everyday phenomenon"; 2) "certain practices are prone to contain disagreement so that this speech act is expected rather than the exception"; 3 ) "disagreeing cannot be seen as an a priori negative act"; and 4) "the ways in which disagreement is expressed - and not only its occurrence per se - will have an impact on relational issues", with "expectations about how disagreement is valued in a particular practice [...] influenc[ing] what forms participants choose". In making these points, the authors draw attention to the pervasiveness of disagreement; and to the importance of addressing context and "frames" (or "structures of expectation", Tannen 1993: 53) in connection with how often and how disagreements are performed and evaluated. Disagreement can, in other words, vary with respect to how conflictual or consensual it is; and it can range from boosted, face-threatening, unexpected disagreement, through to consensual, expected disagreement, to sociable disagreement, and play. Situations where disagreement is not expected (and often dispreferred; Pomerantz 1984) and formulated in a face-threatening manner (e.g., boosted) give rise to what we term "conflictual disagreement"; whereas situations where disagreement is expected and its manifestation pertains to the expected social norms give rise to "consensual disagreement". These are not, however, to be understood as dichotomous, but rather as positions on a cline, with fuzzy boundaries, such that it is also possible for consensual disagreement to become conflictual, or for the two to co-occur within the same exchange. 
In acts of disagreeing, both informational and relational aspects are of importance. As stated by Schneider (2010: 254), it is not possible to sever "the mere transmission of information" from "properties due to the speaker and hearer". "[I]nformational properties" and "relational properties" overlap, "since both the content of a speech act and the manner in which the content is expressed define a relation between the interactants" (Schneider 2010: 254). Analogously a focus on disagreement from the perspective of content needs to be complemented with an interpersonal perspective (Locher and Graham 2010), which explores the interplay between the sharing of information and "relational work" (Locher and Watts 2005, 2008), "relational practice" (Holmes and Schnurr 2005) or "rapport management" (Spencer-Oatey 2000).

In the earliest studies of conflictual disagreement online, it was assumed that both the form and subsequent meaning of the disagreement stemmed directly from the immediate context of the online environment, which was understood with respect to its technological properties. The perceived lack of "social context cues" in online settings compared with offline ones, coupled with the notion that communication online had "few widely shared norms" (Kiesler, Siegel and McGuire 1984: 1126) and was predominantly anonymous, were seen as linked to an increase in uninhibited behaviour online; including both "increases in friendliness and intimacy" and "increase[s] in examples of aggressive and disrespectful behavior" (Reid 1999: 111). With respect to the linguistic realization of disagreement, this suspension of "norms governing disagreement in oral interaction" (Baym 1996: 323 ) in online settings suggested a prevalence of boosted as opposed to mitigated disagreement. And this argument provided grounds for a view of online and offline interaction as fundamentally different. While acknowledging that this view can be enticing given examples of exaggerated disagreement, Baym (1996: 323) argues for a more nuanced interpretation, which recognizes that a multitude of factors influence the realisation and social meaning of disagreements and agreements. In the case of her own research on Usenet (cf. Section 3.1 below), these include its technologocial properties, as well as the context, topic, goals, norms and characteristics of the participants (Baym 1996).

This shift from explanations inspired by "technological determinism" to ones acknowledging that various co-occurring factors shape disagreement online, parallels a broader move from a "first wave" of scholarship on language use online to a second and even third wave (Androutsopoulos 2006: 420-421). Without ignoring the role played by technology, this latter research engages with the multiplicity of ties between form and meaning, and with notions of performance. In recent studies of disagreement, which will be reviewed in Section 3, it is thus typical to find a wide range of factors influencing the performance and evaluation of disagreement in social media.

Concurrent with and related to these changes in approach, there has been a shift from studies on Web 1.0 to Web 2.0. Web 2.0 is largely connected to the emer- 
gence, in the 2000s, of "a new generation of websites [which] integrate applications for interpersonal communication and tools for the management of user-generated content" (Androutsopoulos 2010: 207). These typically include "social networking and media-sharing sites" (Androutsopoulos 2010: 207), such as blogging and microblogging services (including Twitter) and social networking sites (SNS) like Facebook and Instagram, which encourage interactivity, participation and exchange (Androutsopoulos 2010; Yus 2011; and also Heyd, Ch. 6, this volume for blogs, Zappavigna, Ch. 8, this volume for Twitter, and Eisenlauer, Ch. 9, this volume for Facebook). As outlined by Zappavigna (2012: 2), Web 2.0 - or the "social web" - underscores a view of the Internet as a space where relationships are enacted (as opposed to one solely or primarily dedicated to information exchange). The emergence of such sites is clearly of general interest to pragmatics (Yus 2011: 93). With respect to disagreement, a Web 2.0 environment can (at least theoretically) also facilitate the performance of disagreement by participants who can choose to adopt different roles and rely on a gamut of technological affordances for the enactment of these moves (on both an ideational and relational level).

\section{Literature review on conflictual and consensual disagreement}

Viewed as typically dispreferred in early conversation analytic work on casual faceto-face interaction (Pomerantz 1984), literature on conflictual disagreement both offline and online has drawn attention to its potentially face-threatening nature. Conflictual disagreement can have negative effects on one's own or one's interactional partner's face, or both. According to Goffman (1967: 5), face is understood as "the positive social value a person effectively claims for himself [sic] by the line others assume he has taken during a particular contact". Conflictual disagreement can thus potentially lead to relational tensions and influence the likelihood for particular individual and/or group goals to be achieved. It is the potentially face-threatening nature of conflictual disagreement which renders it conceptually similar to flaming (cf. Hardaker 2010, and Ch. 18, this volume) and impoliteness (Graham, Ch. 17, this volume; see also Dynel 2015: 339-340). These overlaps are reflected in the literature, with scholars exploring both flaming and conflict (cf., e.g., Bomberger 2004; Turnage 2007) or disagreement and impoliteness (cf., e.g., Angouri and Tseliga 2010) in various online contexts. Yet despite conceptual overlaps, there are differences. Flaming is typically defined as hostile, aggressive behaviour (Turnage 2007), yet disagreement can range in degree and intensity (e.g., from conflictual to consensual); and whereas impoliteness can emerge in situations where there is no opposition in viewpoint/stance, such opposition is central to the conceptualisation of disagreement (Kakavá 1993).

A review of key literature on disagreement underscores at least seven main, yet often related, foci. These include 
1. the comparative study of disagreements online versus offline (in face-to-face and written interaction);

2. research exploring the role and relationship between social and medium factors (Herring 2007) for the performance and emergent meanings of conflictual and consensual disagreement;

3. an increased focus on sociable disagreement and play, as connected to focus 2;

4. a focus on language and gender with respect to the performance of disagreement online;

5. an increased emphasis on disagreement in dialogic and polylogic interactions, often in connection with questions of participation frameworks;

6. an upsurge in research on disagreement in educational/pedagogical contexts; and

7. increased incorporation of data from different languages.

These foci emerge in scholarship on various e-genres, including computer conferencing (Reid and Hards 1998), email (Tanskanen and Karhukorpi 2008; Haugh 2010), chat (Ong 2011; Vandergriff 2013), blogs and microblogging (Bolander 2012, 2013; Luzón 2013; Anderson and Cermele 2014; Zhang and Kramarae 2014; Dayter 2016), Youtube (Reynolds 2011; Bou-Franch and Blitvich 2014), online newspapers (Lewis 2005; Langlotz and Locher 2012; Angouri and Wodak 2014), newsgroups (Baym 1996), Facebook (Vraga et al. 2015), online courses and learning environments (Peters and Swanson 2004; Lapadat 2007; Monteserin, Schiaffino and Amandi 2010; Lu, Chiu and Law 2011; Maíz-Arévalo 2014), and fora and discussion lists/boards (Hert 1997; Bomberger 2004; Guiller and Durndell 2006; Graham 2007, 2008; Perelmutter 2010; Angouri and Tseliga 2010; Landone 2012; Kádár, Haugh and Chang 2013; Shum and Lee 2013). In what follows, these seven main foci will be illustrated with a selection of studies drawn from these and other works.

\subsection{The comparative study of disagreement online versus offline}

(in face-to-face and written interaction)

Comparisons between disagreement online and offline go back to a general interest in the relative similarities and differences of computer-mediated communication and offline communication prominent in early sociolinguistic research. Here we review the first systematic, empirical study of "Agreements and disagreements in a computer-mediated discussion" by Baym (1996), who sets out to compare the use, nature and meanings of disagreements and agreements in a Usenet newsgroup with disagreements and agreements in letters and face-to-face interactions. For Baym (1996: 320), "Usenet interaction is a hybrid between oral, written, interpersonal, and mass communication"; and its hybridity is important for the meanings and realisation of disagreement and agreement. To explore the effects of hybridity on these moves, Baym (1996) draws comparisons with Pomerantz's (1984) work on the relative preference/dispreference of agreements and disagreements in casual face-to-face interaction, and with Mulkay's $(1985,1986)$ research 
on disagreements and agreements in letter exchanges on scholarly scientific topics.

Based on a qualitative analysis of 70 agreements and 51 disagreements in a Usenet newsgroup storyline (consisting of a total of 542 messages about the soap opera All My Children), Baym (1996: 321) underscores salient similarities and differences with respect to both the characteristics of the moves, as well as their functions. A key similarity between online and offline contexts is that disagreements tend to be "more complex and mitigated" (Baym 1996: 332) than agreements. Mitigation is achieved through various strategies including the use of partial dis/agreement prefaces (like but, though), the acknowledgment of the other party's perspectives, and qualifications which "frame disagreements as resulting from differences in subjective opinion, thus leaving room for the other's viewpoint" (Baym 1996: 337). Differences in the realisation of disagreements and agreements in Usenet stem from both medium and social factors (Herring 2007), i.e., from the technological affordances of the Usenet system coupled with the context framing the interaction and participant characteristics, norms, relationships and goals.

With respect to technology, Baym (1996) highlights the role played by "quotation". Since the Usenet interface allows participants to signal responsiveness via quotation, this becomes the predominant means participants use to mark what message, or more often part of a message, participants are dis/agreeing with. While disagreements are more complex than agreements, both disagreement and agreement moves tended to contain "pervasive elaboration", "reasoning" and "qualification" (Baym 1996: 339). Baym (1996: 340) explains this by referring to the characteristics of the audience, with "[e]laboration [emerging ...] as a way to increase a message's interest value for a mass audience, meeting a wide readership's needs while demonstrating one's own competence at doing so". In addition to quoting and audience, she also underscores norms, topic, purpose, community characteristics and gender as factors important to the form and functions of disagreements and agreements in her data.

\subsection{The role and relationship between social and medium factors}

In their study of two online communities of practice (CofP), Angouri and Tseliga (2010) similarly highlight that a range of factors influence the performance of disagreement and impoliteness. Drawing on data collected from two asynchronous fora (Greek students and professional academics) and follow-up interviews, Angouri and Tseliga (2010: 65) demonstrate the intrinsic role played by norms and expectations for the performance and evaluation of "potentially face-aggravating acts", including "inappropriate and impolite language use". By combining observation with interviews - participants were asked to "talk through" relevant threads and postings "where disagreement is explicitly marked" (Angouri and Tseliga 2010: 65) - they are able to explore practices as well as emergent meanings. While 
the authors rightfully caution from assuming that this provides them with access to participant intentions at the time of the interaction, the interview data enables them to "gather $[\ldots]$ a more in-depth description of the context of interaction in general and the escalation of disagreement in particular" (Angouri and Tseliga 2010: 66).

In addition to stressing community expectations, their research highlights the social factors of participant identity and topic (with political topics, for example, being linked to the prevalence of conflict). It also points to the role played by the medium, notably the "lack of paralinguistic cues" (Angouri and Tseliga 2010). In their data, the lack of paralinguistic cues becomes tied to the prevalence of "[u]nconventional spelling and punctuation" (Angouri and Tseliga 2010: 77). As "a means of accentuating emotions", these spellings and punctuation become a way to express "strong disagreement" and "aggravate face-threatening acts" (Angouri and Tseliga 2010: 77). Often, particularly in the forum to which students contributed, the unconventional spelling and punctuation co-occur with the discourse particle [re] (untranslatable), which functions as a means to "initiate disagreement" (Angouri and Tseliga 2010: 77).

Other research underscoring the variable roles played by particular medium and/or social factors includes Bolander's $(2012,2013)$ study of disagreement, conflict and other discourse moves in a corpus of personal/diary blogs, and Luzón's (2013) research on conflict and identity in academic blog discussions. Importantly, a comparison of this work shows striking differences with respect to the realisation of disagreement, which is seldom mitigated in Luzón's (2013) data, but tends to be dispreferred in Bolander's $(2012,2013)$ data. This may be linked to the fact that the blogs belong to different sub-genres. Luzón's (2013) academic blogs prompted critical exchange of viewpoints as a norm, while Bolander's diary blogs were more oriented towards bonding and consensus. While both scholars acknowledge various factors besides genre for the use of disagreement and conflict, this difference in sub-genre also draws attention to the importance of going beyond a view of a mode or a genre as per se similar to recognising possibilities for internal differences.

As indicated by the discussion of these works, the upsurge of systematic, empirical research on disagreement online was also accompanied by the recognition that the realisation and meaning of disagreement cannot be determined a priori, or on the basis of looking only at form. Rather, ascertaining the meaning and function of disagreement is contingent upon taking into account a whole range of social and medium factors (Herring 2007), which have been shown to influence language use online, including disagreement (cf. particularly Tables 6 and 7 in Bolander 2013: 57, 71). Of particular relevance here are norms and expectations. This is in accordance with our claims about conflictual and consensual disagreement made in Sections 1 and 2. By exploring the range of factors influencing disagreement online, scholars have progressively highlighted the prominence of both conflictual and consensual disagreement. Thus, while Baym (1996), for example, draws 
attention to the fact that disagreements tend to be mitigated relative to agreement, she also underscores that they are positively evaluated and seen as compatible with the Usenet newsgroup's goals. Indeed, since "[d]isagreement invariably involves the contribution of different interpretive resources, [it] thus facilitates the group's primary goal" (Baym 1996: 341). In this sense, disagreements are both conflictual, face-threatening or potentially face-threatening, as suggested by the strong presence of mitigation, and consensual, by being conducive to community formation and maintenance.

\subsection{Sociable disagreement and play}

Recent research on social media has also begun to study sociable disagreement, conceptualised here as a particular kind of consensual disagreement. The notion of sociable disagreement can be traced back to research conducted in the early 1980s (cf. e.g., Tannen 1981; Schiffrin 1984). Put forward to account for and draw attention to cross-cultural differences in the social meaning of disagreement, such research draws attention to the possibility that discourse which has the form of (strong) disagreement is not necessarily face-threatening to its participants. It can instead be reflective of particular norms and relationships between participants which render the apparent conflict sociable. As stated by Schiffrin (1984: 331), "sociable argument" constitutes "a speech activity in which a polarizing form has a ratificatory meaning". Introduced by Schiffrin (1984) in connection with her work on Jewish Americans in Philadelphia, sociable disagreement accounts for the function of typically strong disagreements as resources and markers of solidarity (Schiffrin 1984: 332). In addition to highlighting cultural differences in the relative preference of disagreements and agreements (without homogeneising across cultures), "sociable argument" underscores the key role played by participant relationships. Sociable disagreements "seem designed to show that the interactants' relationship is close enough to withstand what would be considered by outsiders to be verbal assaults" (Schiffrin 1984: 331).

While demonstrating that disagreement and conflict can take on different forms and functions, research on language use in social media has only recently engaged with sociable disagreement. In doing so, it has extended and adapted the notion to online settings, highlighting the role of sociability, participant relationships, humour, mitigation and play, in particular. Perhaps the earliest of these studies is Weber's (2011) research on the socialisation of newcomers into a Usenet newsgroup for sexual abuse survivors. Drawing on extensive data (over 2000 messages) obtained during 1.5 years of regular observation and archiving, Weber hones in on a dispute which took place during two weeks and which involved a total of 16 participants and around 50 messages. Part of the dispute involves two "regular" participants, who seemingly engage in a conflictual disagreement. Yet as Weber (2011) demonstrates, the participants draw on a variety of resources to mark the 
dispute as non-threatening. These include "statements which refer to or imply a durative relationship between the two combatants", "the use of emoticons which key playfulness throughout the argument" and "the presence of politeness behaviors and the absence of flame-like behaviors in messages posted in the same thread by and to other participants" (Weber 2011). Based on a close examination of these cues, Weber (2011) underscores that such "play" is unmarked and emerges as a frame shaping the way these two participants interact with one another, although it does not constitute an expected practice for the group as a whole. In this sense, the example underscores the co-presence of consensual (sociable) as well as conflictual disagreement.

Bolander $(2012,2013)$ also draws attention to the role played by participant relationships for the enactment of sociable disagreement in her study of eight personal/diary blogs. Here, too, the sociable disagreement involves two participants, who use the comments section of a blog, written by a mutual friend, to play and banter with one another. Drawing explicitly on Schiffrin's (1984) notion of "sociable argument", Bolander $(2012,2013)$ explores the ways these participants make manifest that their relationship is not fleeting (for example through references to a shared offline workspace), while highlighting the creative use of paralinguistic features for the performance of the sociable argument, and the presence of "bonding humour", which serves to mark the "disagreement as sociable and to index an existing (close) relationship" (Bolander 2013: 67). For Bolander (2012, 2013), the sociable disagreement exchange is especially salient because it gives rise to reader-reader interaction, an otherwise less typical interactional frame in the blog corpus (as discussed in Section 3.4 below).

Ardington (2013) adds to this discussion by underscoring the fluid relationship between sociable and conflictual disagreement. Her focus is a collaborative online report produced by staff members of a large Australian metropolitan university who felt threatened by the Vice Chancellor's video message announcing staff cuts, and an ensuing multiparty asynchronous forum discussion. She is thereby particularly interested in exploring the "relational aspects of conflict talk for this social group (academic community of practice) in text-based CMC from an interactional sociolinguistic perspective" (Ardington 2013: 170). Using the last paragraph of the report and posts from the asynchronous discussion as data, Ardington (2013) highlights a shift from sociable to conflictual disagreement in the course of the discussion. The early stages of the discussion are characterised as sociable: "posts reflect a playful aggressive frame" (Ardington 2013: 174) and are co-constructed by posters (Ardington 2013: 174), who also take "enjoyment" (Ardington 2013: 179) from the creative mocking and critique of the Vice Chancellor and other senior management personnel. Here humour plays a key role, notably "abbreviated address forms, mitigated forms, complimenting actions, irony, metaphor and recycling of others' words" (Ardington 2013: 185). Yet in the course of the discussion, the frame shifts from a "playful" to a "serious, more adversarial frame where 
co-present participants become direct targets of the talk" (Ardington 2013: 181). This shift is marked by an increase in personal criticism - with both "direct and indirect personal attacks" (Ardington 2013: 183) gaining in currency. Since those critiqued are expected to respond, to "justify, defend, or counterattack", the result is an overall "spiraling of conflict" (Ardington 2013: 184).

This move from sociable to conflictual disagreement indicates that there is often no straightforward means of deciding when "sociable argument" becomes "serious conflict" (Ardington 2013: 172). While this point has been made for research offline, Ardington's (2013) contribution extends the conversation to social media. When reviewing literature for this chapter, we too became aware of the fuzzy boundaries between conflictual and consensual disagreement (including sociable disagreement). While there are differences between these forms, "the boundary between play and non-play is a contested and difficult space" (Ardington 2013: 172). Addressing how this boundary is marked and enacted is reliant on close empirical analysis of disagreement, particularly of latent and emergent norms and frames, or expectations. Going beyond notions of preference and dispreference, this foregrounding of norms allows for and highlights the importance of the parallel inclusion of different types of disagreement.

\subsection{Language and gender}

A further topic which has received widespread attention in research on disagreement online is language and gender. It, too, stems from an interest in comparisons between offline and online settings for the pragmatics of disagreement in various modes of computer-mediated communication (cf. also Section 3.1). Fuelled by the question of whether the Internet would bring about more gender parity compared with offline environments, early research on language and gender online explored differences between male and female communicative styles with respect to issues of power and dominance (cf. e.g., Herring 1993, 2001). It then progressed to more specific analyses of types of differences, including a focus on conflictual disagreement and flaming. Herring's (1994) paper "Politeness in computer culture: when women thank and men flame", for example, is based on the assumption that men and women not only behave differently online, but also differ with respect to "ideas of what constitutes appropriate and inappropriate behavior on the net" (Herring 1994: 278). Drawing on an analysis of nine discussion lists with varying percentages of female subscribers, and an anonymous survey on net etiquette, Herring (1994: 291) argues that whereas women value "politeness", men adopt an "ethic of anarchic self-determination and vigorous debate". As Herring (2003: 207) maintains, research on language and gender online highlights differences between male and female users of CMC with respect to "verbosity, aggressiveness, use of profanity, politeness (and rudeness), typed representations of smiling and laughter, and degree of interactive engagement". Similar claims regarding differences in 
male and female linguistic behaviour online have been made by other scholars, for example, by Savicki (1996) with respect to Internet discussion groups, Arnold and Miller (1999) for home pages, and Guiller and Durndell (2006) for educational online discussion groups.

Paralleling a more general development in sociolinguistics (cf., e.g., Eckert and McConnell-Ginet 1992), Rodino (1997) argues for the need to shift from a view of gender online as a "stable category" towards one which acknowledges its perpetual construction. She thereby critiques research which reifies "binary gender", calling instead for the exploration of the multitude of ways "gender is experienced and exhibited" in various contexts and through differing practices (Rodino 1997). In doing so, she does not reject the possibility for participants to "reflect and recreate gender bifurcation" (Rodino 1997). As her work on communication in Internet Relay Chat (IRC) makes manifest, her participants present and construct gender in various ways, including both "stable representations" and "contradictory performances" (Rodino 1997; see also Huffaker and Calvert 2005). While Rodino (1997) does not deal with disagreement and conflict, her arguments clearly have implications for the study of these moves with respect to gender online.

However, and as Rodino (1997) argues, this view of gender should not preclude a focus on women's oppression online. Thus, paralleling and largely also motivating research is an interest in power relations and the continued enactment of aggression against women online. As Anderson and Cermele (2014: 289) have argued in a recent paper on "Public/private language aggression against women: Tweeting rage and intimate partner violence", verbal aggression against women often "reproduce[s] a binary construction of gender that justifies women's subordinate status". To demonstrate the pervasiveness of verbal aggression against women, they explore two different sources of data: a corpus of tweets (which deal with a "critical analysis of gendered representations and the under-representation of female protagonists in video games" [@femfreq]; Anderson and Cermele 2014: 275) and a corpus of Civil Protection Order petitions (filed with the aim of allowing victims of domestic abuse to seek protection from the civil courts). Yet whereas overt verbal aggression which is gendered and which involves threats of violence is the norm in the Civil Protection Order petitions, the "dominant pattern of sexist verbal aggression in tweets makes use of subtle strategies that construct women as weak, lesser, and other, while retaining the veneer of polite and reasonable discourse" (Anderson and Cermele 2014: 289, emphasis in original; cf. also Bou-Franch and Garcés-Conejos Blitvich 2014). These strategies include claims that women are not as capable gamers as men, constructions of women as outsiders (and thus less capable), language suggesting that @femfreq is weak, as well as "projections" of sexism back onto the target (such that the target of abuse is claimed to be acting in a sexist manner) (Anderson and Cermele 2014: 286-288). As the authors underscore, both differences as well as the general prevalence of aggression in the two sources of discourse can be linked to the ways the sets of 
data are simultaneously public and private. Thus "tweets may be considered 'public' speech that is assumed to be impersonal and protected by ideologies of free speech, and private speech that is protected by the conventions that it is backstage talk that should not be taken too seriously"; and the Protection Order petitions as "public in that [they] become [...] part of an official court record" while being based on private encounters between partners (Anderson and Cermele 2014: 289, emphasis in original). Encouraging a view which takes account of the complex ways context and technology shape language use, this research demonstrates that there is no tie between more covert, indirect forms of verbal aggression and level of threat, such that both forms - overt and covert - serve to reinforce women's subordinate societal status (Anderson and Cermele 2014: 290).

\subsection{Disagreements in dialogic and polylogic interactions}

Recent research on disagreement has also progressively begun to explore performance in connection with participation frameworks and broader questions of interactivity. This is linked to the shift to Web 2.0 (cf. Section 2), which has prompted an upsurge in research literature on the complexity of participation and participation frameworks in social media (cf., e.g., the papers in Dynel and Chovanec 2015). As Chovanec and Dynel (2015) outline, such questions are linked to types of participants, degrees and layers of participation, issues of audience, reach and transmission, and (disappearing) boundaries between public and private. These are all also pertinent issues for the study of disagreement.

Bolander's $(2012,2013)$ research on language and power in eight personal/ diary blogs, for example, highlights ties between participation framework, interactional patterns, and particular discourse moves, including disagreement and agreement. With respect to the participation framework, quantitative and qualitative analysis of 841 comments shows that bloggers emerge as dominant participants to whom the majority of disagreements and agreements are directed, and who agree and disagree with their readers (in responses to reader comments). Via a parallel focus on how these disagreement and agreement turns are made responsive (i.e., how interlocutors mark to whom they are directing their turn, cf. also the discussion of Baym 1996 in Section 3.1), she highlights ties between participation framework and types of responsiveness. Thus whereas readers tend to be more explicit (e.g., naming, quoting, format tying) when directing disagreements and agreements at other readers, when addressing the blogger they tend to rely on less explicit markers of responsiveness. For Bolander $(2012,2013)$ this is reflective of both the latent, structural properties of the blog, which give rise to an a priori division of rights and obligations between blogger and readers, and the emergent participation framework, which reinforces the blogger's privileged status, as becomes apparent through the actual degree and emergence of interaction in the comments. 
For Luzón (2013: 118), whose research on academic blogs is discussed in Section 3.2 above, conflict in blog discussions is constructed across exchanges "with several interlocutors taking sides and responding to various comments in the discussion", a finding she links with the blog's "medium affordances" which facilitate "polylogues". Research on online polylogues is typically traced back to Marcoccia's (2004) study of participation framework in three online newsgroups. As Bolander $(2012,2013)$ argues, the emergence of polylogues in blogs is linked to the types of discourse move that are used. In her data, particular moves, notably disagreement, agreement and criticism, become associated with interactions going beyond two or three turns and involving several participants. (Cf. also Reynolds 2011 for a discussion of how particular types of "uncontroversial questions" serve to elicit certain answers in data on protests posted to YouTube.)

An exploration of polylogues is also central to Bou-Franch and Blitvich's (2014) research on conflictual disagreement in YouTube. Working with a corpus of comments following a public service announcement on the topic of teenage homosexuality (posted by a Spanish organisation), they explore the emergence and development of conflict (beginning, middle, end/closing). Advanced for the study of conflict in offline settings, existing models and taxonomies on stages of conflict have not been applied to massive online polylogues. In YouTube, considerations of anonymity and asynchronicity (the fact that messages are not exchanged in realtime, but with a time lag), coupled with YouTube's facilitating of multi-participant interaction are central to understanding how conflict emerges, is made meaningful and co-constructed (Bou-Franch and Blitvich 2014: 20, 21). By virtue of the persistent status of text on YouTube, researchers are also provided with "unprecedented access [...] to the diachronic unfolding of conflict" (Bou-Franch and Blitvich 2014: 21), which has not yet received systematic attention in studies of language in social media (but see DuVal Smith 1999; Reid 1999). Combining qualitative and quantitative methods, Bou-Franch and Blitvich (2014: 32) argue for the importance of exploring both the synchronic and diachronic construction of conflictual disagreement in YouTube. On the basis of their analysis they argue for the need to problematize existing conceptualisations of "beginnings, middles and ends" (Bou-Franch and Blitvich 2014: 33). Rather than viewing these stages as "reified constructs", closer attention needs to be paid to the ways in which multi-participation and identity facilitate the maintenance of a "continuous middle", and thus to the tendency for conflict to be "on-going and unresolved" (Bou-Franch and Blitvich 2014: 33). To highlight the "multifunctionality of utterances", the "multi-sequentiality" of the conflict and the fact that conflict tends not to be resolved, they propose an alternate, adapted model outlining how conflict unfolds in massive polylogues (thereby building on previous research by Dobs and Garcés-Conejos Blitvich 2013, and Bousfield 2007).

Questions of interactive patterns, participation and collaboration also feature in Lewis' (2005) study of argument in French political discussions, Taskanen and 
Karhukorpi's (2008) research on repair and the negotiation of affiliation in email, Hodson-Champeon's (2010) work on intertextuality in racially antagonistic discourse, Kleinke's (2010) analysis of disagreements and "emergent networks" in English and German-language public newsgroups, and Perelmutter's (2010) study of Russian complaint discourse and the performance of relational work across conversations. Despite different foci, each of these papers points to the importance of empirically examining how particular technological affordances become entangled with the ways participants use language to perform disagreement. By highlighting the variety of ways participants use language creatively in an attempt to achieve individual or group goals, they also underscore the need to move away from a priori assumptions about straightforward ties between technological affordances and resulting practices.

\subsection{Research on disagreement in educational/pedagogical contexts}

A further strand of research explores disagreement in learning environments (Monteserin, Schiaffino and Amandi 2010; Roschelle et al. 2010; Lu, Chiu and Law 2011; Chiu and Cowan 2012; Verecellone-Smith 2012; Vandergriff 2013; Maíz-Arévalo 2014). Some of this work also has a cross-cultural focus, for example, Maíz-Arévalo's (2014) study of disagreement and pragmatic rules in English as a Lingua Franca discourse (cf. also Chiu and Cowan 2012). Choosing to analyse disagreement by virtue of its typically face-threatening nature and "disruptive potential”, Maíz-Arévalo's (2014) intercultural pragmatic approach aims to ascertain how students from various cultural backgrounds and with different degrees of proficiency in English enact disagreement. On the basis of an analysis of asynchronous mediated discussion data, the research highlights that mitigated disagreement is more prominent than strong disagreement, and that students with a greater degree of proficiency in English draw on a wider range of strategies, tending "to follow the same strategies as native speakers do in order to avoid facethreat” (Maíz-Arévalo 2014: 220).

\subsection{Incorporation of data from different languages}

While research on disagreement has prioritised English-language data, as shown in Sections 3.1-3.5, there seems to be a progressive focus on other languages (cf., e.g., Angouri and Tseliga 2010 for Greek; Perelmutter 2010 for Russian; Kleinke 2010 for German and English; Landone 2012 for Spanish; Enama 2014 for French and English; and Kádár, Haugh and Chang 2013; Shum and Lee 2013; and Zhang and Kramarae 2014 for different varieties of Chinese). As with the other themes discussed in this section, this gradual inclusion of other languages and varities in connection with disagreement parallels a broader shift in the study of language and language use online. Marked explicitly by the publication of Danet and Herring's 
(2007) The Multilingual Internet, research has progressively done justice to the fact that the Internet, while still dominated by English, is a multilingual space.

Thus, Kádár, Haugh and Chang (2013), for example, explore similarities and differences in the ways Mainland Chinese and Taiwanese discussion board participants variously enact verbal aggression and impoliteness. Focusing on nationalistic discourse, they examine "the role of perceptions of national identity and national face in occasioning instances of aggression" (Kádár, Haugh and Chang 2013: 345), notably with respect to terms of address and reference. Combining a quantitative and qualitative analysis of web-based text produced by Mainland Chinese or Taiwanese, as well as discussion board data, the authors demonstrate salient differences, with the former tending to use "associative identity practices" (whereby pan identity claims are indexed; Kádár, Haugh and Chang 2013: 347) and the latter "dissociative identity practices" (whereby distance to the nation is underscored; Kádár, Haugh and Chang 2013: 348). When interacting with one another, in other words, the Mainland Chinese are more likely to use the "ostensibly polite forms tongbaomen ('compatriots') or xiongdijiemei ('brothers and sisters')", whereas the Taiwanese tend instead to employ "abusive terms, negative metapragmatic discourse on the use of such pan-Chinese forms of address/reference, marked use of deferential forms, as well as sarcasm" (Kádár, Haugh and Chang 2013: 367). Interpreting this difference with respect to "broader macro-discourses on national identity", the authors argue for the importance of studying face not only at the "interpersonal", but also at the "intergroup" level (Kádár, Haugh and Chang 2013: 344).

\section{Key issues: From the challenge of context to indexing emotion}

The discussion in Section 3 highlights central developments in the study of disagreement in social media. In doing so, it draws attention to changes in technology and approach, notably a shift to Web 2.0 and the progressive emphasis on the multifaceted nature of disagreement online, on conflictual and consensual disagreement, and on performance and play. In this section, we review two issues which have begun to receive more attention in studies of disagreement: context as related to the complex relationship between online and offline spaces; and the indexing of emotion through written language in social media.

The first of these concerns the need for social media scholars to tackle how context is shaped and brought into being. This includes thinking about context both in terms of technological affordances as well as with respect to participants whose use of technology is shaped by various factors linked to but also going beyond the immediate affordances of the particular site in question. As Jones (2004) maintains, issues of context are intricately linked to questions of the border between "offline" and "online" and more specifically to its usefulness. In his (2004) paper 
on "The problem of context in computer-mediated communication", he argues that there has been a tendency for research on computer-mediated communication to treat interaction as if it "takes place in a kind of virtual vacuum with little connection to the material worlds of the people sitting in front of computer screens and producing the words that analysts spend so much time dissecting and interpreting" (Jones 2004: 21). If we acknowledge that the context for social media interactions does not exist a priori, but is enacted and made into context by participants, the boundary between offline and online/virtual and real begins to collapse (Jones 2004; cf. also Barton and Lee 2013; Bolander and Locher 2014).

For the study of language use and disagreement online, problematizing context has both epistemological as well as methodological implications. Thinking about disagreement, it means considering the possibility that disagreement can be realised across modes of social media as well as across "lines" (offline/online), while critically reflecting on the ways different sources of data can help answer various research questions pertaining to the use and emergent meanings of disagreement. While much research on these issues still needs to be done, Sections 2 and 3 show scholars considering the interplay between social and medium factors, as well as drawing on mixed methods and the use of different sources of data to explore disagreement from multiple angles.

As shown in Angouri and Tseliga (2010: 66), for example, using interview data in addition to the analysis of asynchronous fora data provides greater insight into "the context of interaction", and thus into how disagreement and impoliteness are viewed by participants themselves. It allows them, in other words, to more fully explore what these moves mean and how they are evaluated; and thus to reflect upon the relationship between evaluations and practices. Similarly Bolander $(2012,2013)$ works with interview data collected from bloggers on a range of topics (pertaining, for example, to language use, and the bloggers' roles and relationships with their readers), as a means to complement her discourse analysis of the pragmatics of disagreement, conflict and other moves in blog posts and comments.

More recently, Niemi (2014) highlights the fuzzy boundaries between online and offline in her analysis of children's classroom disputes and threats. Using Goffman's (1974) concept of frame and conversation analysis, she explores the ways two young boys (best friends in the same class at school) shift between different "pretend frames" - from video games as well as "real life" - in enacting a dispute. Although the video game frames cannot be acted on in the classroom setting, by drawing on them as a resource the boys bring them into the classroom. This "video game activity", in other words, "can be 'done' in the classroom", a finding Niemi (2014: 119) takes as indicative of occurrences in the video game world influencing what happens in "the real world", and vice versa. For the pragmatics of disagreement, this article draws attention to the importance of considering the possibility that offline sites can also constitute or rather become, if we 
think of context as something which is enacted and emergent, a key space for the study of online language use and practices.

Returning to online spaces, context has also become more complex for interaction in social media as a result of what Marwick and boyd (2010: 122) term "context collapse". This notion refers to the fact that many types of social media, notably social networking sites, "flatten [...] multiple audiences into one". Despite the possibility to manage privacy by creating different accounts for different audiences, context collapse means "participants must contend with groups of people they do not normally bring together, such as acquaintances, friends, co-workers, and family" (Marwick and boyd 2010: 122). As a result, users strategically employ resources in connection with impression management, and as a means to navigate between the "portray[al ... of] an authentic self and an interesting personality" (Marwick and boyd 2010: 122). While typically explored in connection with the construction and performance of online identity, and more recently language choice and multilingualism (Androutsopoulos 2014), Vraga et al. (2015) extend the discussion to disagreement online. Focusing on Facebook, they combine interview with survey data of young adults to explore ties between the likelihood for conflictual political disagreement on Facebook and variation in participants" "perceptions of the political climate on Facebook" (Vraga et al. 2015: 282). In addressing these questions, they pay close attention to the way audience heterogeneity (in connection with "context collapse") emerges as relevant for individual perceptions of political disagreement on Facebook. While their focus is not pragmatic, their results have implications for issues of how disagreements are realised, notably their finding that perceptions of political disagreement on Facebook are strongly linked to tone, as well as to the participants' Facebook network structures and size (Vraga et a. 2015: 288).

Another strand of recent research has begun to explore how emotion in disagreement is cued in written language. In doing so, such research demonstrates that social media is not impoverished relative to offline interaction (cf. Section 2 for a discussion of the cues-filtered out approach). Langlotz and Locher (2012), for example, study ties between emotion, disagreement and relational work via a quantitative and qualitative analysis of 120 English postings from MailOnline. They thereby demonstrate that emotion can be indexed via "expression" (including both linguistic means like "name calling" and "verbalisation of emotional reaction", as well as graphic means like "smileys"), via "implication" (where implicature is used to index emotional stance) and via "description" (through the use of "emotion words" and "verbal descriptions/ascriptions of verbal states"; Langlotz and Locher 2012: 1600-1601). As these examples highlight, the possibility to index emotional stance is varied, despite it being either linguistic or graphic (as opposed to visual and/or aural).

In addition to highlighting participant creativity with respect to the use of written language for emotional stance, this research demonstrates the polysemy of 
emotive cues. As outlined, for example, by Vandergriff in her (2013:1) article on conflictual chat discourse, the meanings of CMC cues are highly context dependent. Focusing on the use of cues amongst advanced foreign language learners of German tasked with negotiating consensus on a moral dilemma on chat (Vandergriff 2013: 2,3), she argues for a move away from trying to map offline emotive cues onto online ones, towards an exploration of "how CMC participants adopt the semiotic system of chat to their communicative needs" (Vandergriff 2013: 2). Central to her argument is the finding that "form-meaning correlations of CMC cues only emerge in context" (Vandergriff 2013: 8), a result which is compatible with Langlotz and Locher's (2012) results discussed above. She thereby also demonstrates that these cues tend not to emerge alone, but in interaction with other cues, both verbal and nonverbal, in contexts of emotive communication. By highlighting the ways emotion is indexed online through written language (linguistic, graphic, paralinguistic), both Langlotz and Locher (2012) and Vandergriff (2013) remind us of the importance of not bracketing out or ignoring the multifacetedness of written language in light of the increased multimodality of social media.

\section{Conclusions}

This chapter begins by underscoring that there is no straightforward relationship between form and function, such that looking solely at the linguistic manifestation of disagreement cannot be taken as grounds for ascertaining what disagreement might mean to participants involved in interaction in social media. Coupled with a view of language as always informed by both informational and relational properties, we underscore the importance of paying close attention to how disagreements are realised, to evidence of whether they are expected, and to possible implications for face. The importance of treating disagreement as multifaceted, of recognising that there is no straightforward form-function relationship, and that meanings of disagreement can shift in the course of a single interaction are thus all points which emerge from our review of disagreement. In Section 2 of the paper, we problematize these issues via a discussion of a shift in epistemology in research on language use online, via a focus on Web 2.0 environments, and via a cautious differentiation between conflictual and consensual (including sociable) disagreement. The largest section of the paper, Section 3, is then devoted to exploring seven foci highlighted as pertinent in the literature we reviewed on disagreement in social media: the comparative study of disagreements online versus offline (in face-to-face and written interaction); research exploring the role and relationship between social and medium factors (Herring 2007) for the performance and emergent meanings of conflictual and consensual disagreement; an increased focus on sociable disagreement and play; research on language and gender with respect to the performance of disagreement online; an increased emphasis on disagreement in dialogic and poly- 
logic interactions, often in connection with participation frameworks; an upsurge in research on disagreement in educational/pedagogical contexts; and incorporation of data from various languages as part of enhanced recognition of the web as a multilingual space.

Subsequently we turned to two issues we feel are of import for scholars interested in disagreement in social media: context as related to the multifarious relationship between online and offline spaces, and the indexing of emotion through written language in social media. In many ways, these issues also constitute our outlook. The first prompts for further teasing out of the implications of increasingly blurring boundaries within different forms of social media as well as across lines (online/offline) for pragmatic research on particular practices, including but not limited to disagreement. And the second calls for increased studies on modality, via further analysis of the ways disagreement can be enacted through different modes, along with careful consideration of how these modal affordances offer additional layers for reflecting on social and medium factors shaping language use.

\section{Acknowledgments}

Many thanks to Aline Bieri for her assistance in compiling literature and addressing many style issues. For feedback on this chapter, we thank Wolfram Bublitz and Christian Hoffmann. All remaining faults are our own.

\section{References}

Androutsopoulos, Jannis

2006 Introduction: Sociolinguistics and computer-mediated communication. Journal of Sociolinguistics 10(4): 419-438. http://www.blackwell-synergy.com/ doi/abs/10.1111/j.1467-9841.2006.00286.x.

Androutsopoulos, Jannis

2010 Localizing the global on the participatory web. In: Nikolas Coupland (ed.), The Handbook of Language and Globalisation, 203-231. Malden, MA: Wiley-Blackwell.

Androutsopoulos, Jannis

2014 Languaging when contexts collapse: Audience design in social networking. Discourse, Context and Media 4-5: 62-73.

Anderson, Kristin L. and Jill Cermele

2014 Public/private language aggression against women: Tweeting rage and intimate partner violence. Journal of Language Aggression and Conflict 2(2): 274-293. doi: 10.1075/jlac.2.2.05and.

Angouri, Jo and Miriam A. Locher

2010 Disagreement on and off line. Paper presented at the Fifth International Symposium on Politeness, Basel. 
Angouri, Jo and Theodora Tseliga

2010 "you HAVE NO IDEA WHAT YOU ARE TALKING ABOUT!" From $e$-disagreement to e-impoliteness in two online fora. Journal of Politeness Research 6(1): 57-82.

Angouri, Jo and Ruth Wodak

2014 'They became big in the shadow of the crisis': The Greek success story and the rise of the far right. Discourse and Society 25(4): 540-565.

Ardington, Angela

2013 Negotiating shared perspectives that move in and out of sociability: Play and aggression in technologically mediated communication. Journal of Language Aggression and Conflict 1(2): 165-193. doi: 10.1075/jlac.1.2.03ard.

Arnold, Jill and Hugh Miller

1999 Gender and web home pages. Paper presented at the CAL99 Virtuality in Education Conference, London. http://ess.ntu.ac.uk/miller/cyberpsych/cal99.htm.

Barton, David and Carmen Lee

2013 Language Online. Investigating Digital Texts and Practices. London: Routledge.

Baym, Nancy

1996 Agreements and disagreements in a computer-mediated discussion. Research

Bolander, Brook on Language and Social Interaction 29(4): 315-345.

2012 Disagreements and agreements in personal/diary blogs: A closer look at responsiveness. Journal of Pragmatics 44: 1607-1622.

Bolander, Brook

2013 Language and Power in Blogs: Interaction, Disagreements and Agreements Amsterdam/Philadelphia: Benjamins.

Bolander, Brook and Miriam A. Locher

2014 Doing sociolinguistic research on computer-mediated data: A review of four methodological issues. Discourse, Context and Media 3: 14-26. doi: http:// dx.doi.org/10.1016/j.dcm.2013.10.004.

Bomberger, Ann M.

2004 Ranting about race: Crushed eggshells in computer-mediated communication. Computers and Composition: An International Journal for Teachers of Writing 21(2): 197-216. doi: 10.1016/j.compcom.2004.02.001.

Bou-Franch, Patricia and Pilar Garcés-Conejos Blitvich

2014 Conflict management in massive polylogues: A case study from YouTube. Journal of Pragmatics 73: 19-36. doi: 10.1016/j.pragma.2014.05.001.

Carnevale, Peter and Tahira Probst

1997 Conflict on the internet. In: Sara B. Kiesler (ed.), Culture of the Internet, 233255. Mahwah, NJ: Lawrence Erlbaum.

Chiu, YiChing Jean and John Cowan

2012 Helping Eastern students to master Western critical thinking. Asia Pacific Education Review 13(1): 103-111. doi: 10.1007/s12564-011-9189-2.

Chovanec, Jan and Marta Dynel

2015 Researching interactional forms and participant structures in public and social media. In: Marta Dynel and Jan Chovanec (eds.), Participation in public and social media interactions, 1-23. Amsterdam/Philadelphia: Benjamins. 
Collins, Mauri

1992 Flaming: The relationship between social context cues and uninhibited verbal behavior in computer-mediated communication. http://www.mediensprache. net/archiv/pubs/2842.htm.

Danet, Brenda and Susan Herring (eds.)

2007 The Multilingual Internet: Language, Culture, and Communication Online. New York: Oxford University Press.

Dayter, Daria

2016 Discursive Self in Microblogging: Speech Acts, Stories and Self-praise Amsterdam/Philadelphia: Benjamins.

DuVal Smith, Anna

1999 Problems of conflict management in virtual communities. In: Marc Smith and Peter Kollock (eds.), Communities in Cyberspace, 134-163. New York: Routledge.

Dynel, Marta

2015 The landscape of impoliteness research. Journal of Politeness Research 11(2): 329-354.

Dynel, Marta and Jan Chovanec (eds.)

2015 Participation in Public and Social Media Interactions. Amsterdam/Philadelphia: Benjamins.

Eckert, Penelope and Sally McConnell-Ginet

1992 Communities of practice: where language, gender, and power all live. In: Kira Hall, Mary Bucholtz and Birch Moonwomon (eds.), Locating Power. Proceedings of the Second Berkeley Women and Language Conference, 89-99. Berkeley, CA: Women and Language Group.

Enama, Patrick Rodrigue Belibi

2014 Information Structure, Agreement and Disagreement in English and French Asynchronous Online Discussion. MA Thesis. Albany: State University of New York at Albany.

Goffman, Erving (ed.)

1967 Interaction Ritual: Essays on Face-to-face Behavior. Garden City, NY: Anchor Books.

Goffman, Erving

1974 Frame Analysis. An Essay on the Organization of Experience. Cambridge, MA: Harvard University Press.

Graham, Sage Lambert

2007 Disagreeing to agree: Conflict, (im)politeness and identity in a computer-mediated community. Journal of Pragmatics 39(4): 742-759.

Graham, Sage Lambert

2008 A manual for (im)politeness?: The impact of the FAQ in electronic communities of practice. In: Derek Bousfield and Miriam A. Locher (eds.), Impoliteness in Language. Studies on its Interplay with Power in Theory and Practice, 281-304. Berlin/Boston: de Gruyter.

Guiller, Jane and Alan Durndell

2006 'I totally agree with you': Gender interactions in educational online discussion groups. Journal of Computer Assisted Learning 22(5): 368-381. doi: 10.1111/j.1365-2729.2006.00184.x. 
Hardaker, Claire

2010 Trolling in asynchronous computer-mediated communication: From user discussions to academic definitions. Journal of Politeness Research 6: 215-242.

Haugh, Michael

2010 When is an email really offensive?: Argumentativity and variability in evaluations of impoliteness. Journal of Politeness Research 6(1): 7-31. doi: 10.1515/

Herring Susan C. jplr.2010.002.

1993 Gender and democracy in computer-mediated communication. Electronic Journal of Communication 3(2). http://ella.slis.indiana.edu/ herring/ejc.doc.

Herring, Susan C.

1994 Politeness in computer culture: Why women thank and men flame. In: Mary Bucholtz, A.C. Liang, Laurel A. Sutton and Caitlin Hines (eds.), Cultural Performances: Proceedings of the Third Berkeley Women and Language Conference, 278-294. Berkely, CA: Berkeley Women and Language Group.

Herring, Susan C.

2001 Gender and power in online communication. Center for Social Informatics Working Papers, no. WP-01-05. https://scholarworks.iu.edu/dspace/bitstream/ handle/2022/1024/WP01-05B.html? sequence=1.

Herring, Susan C.

2007 A faceted classification scheme for computer-mediated discourse.Language@, Internet 4. http://www.languageatinternet.de/articles/2007.

Hert, Philippe

1997 The dynamics of on-line interactions in a scholarly debate. The Information Society 3(4): 329-360.

Hodsdon-Champeon, Connie

2010 Conversations within conversations: Intertextuality in racially antagonistic online discourse. Language@Internet 7(10). http://nbn-resolving.de/urn:nbn:de:0009-7-28206.

Homes, Janet and Stephanie Schnurr

2005 Politeness, humor and gender in the workplace: Negotiating norms and identifying contestation. Journal of Politeness Research 1(1). doi: https://doi.org/ 10.1515/jplr.2005.1.1.121.

Huffaker, David A. and Sandra L. Calvert

2005 Gender, identity, and language use in teenage blogs. Journal of Computer-Mediated Communication 10(2). doi: 10.1111/j.1083-6101.2005.tb00238.x.

Jones, Rodney

2004 The problem of context in computer-mediated communication. In: Philip LeVine and Ron Scollon (eds.), Discourse and Technology: Multimodal Discourse Analysis, 20-33. Washington D.C.: Georgetown University Press.

Kádár Dániel, Z., Michael Haugh and Melody Chang Wei-Lin

2013 Aggression and perceived national face threats in Mainland Chinese and Taiwanese CMC discussion boards. Multilingua 32(3): 343-372. doi: 10.1515/ multi-2013-0016.

Kakavá, Christina

1993 Negotiation of Disagreement by Greeks in Conversations and Classroom Discourse. Doctoral Thesis, Washington D.C.: Georgetown University. 
Kiesler, Sara, Jane Siegel and Timothy W. McGuire

1984 Social psychological aspects of computer-mediated communication. American Psychologist 39(10): 1123-1134. doi: 10.1037/0003-066x.39.10.1123.

Kleinke, Sonja

2010 Interactive aspects of computer-mediated communication: 'Disagreement' in an English and a German public news group. In: Sanna-Kaisa Tanskanen, Marja-Liisa Helasvuo, Marjut Johansson and Mia Raitaniemi (eds.), Discourses in Interaction, 195-222. Amsterdam/Philadelphia: Benjamins.

Landone, Elena

2012 Discourse markers and politeness in a digital forum in Spanish. Journal of Pragmatics 44(13): 1799-1820. doi: 10.1016/j.pragma.2012.09.001.

Langlotz, Andreas and Miriam A. Locher

2012 Ways of communicating emotional stance in online disagreements. Journal of Pragmatics 44(12): 1591-1606.

Lapadat, Judith C.

2007 Discourse devices used to establish community, incerase coherence, and negotiate agreement in an online university course. Journal of Distance Education 21(3): 59-92.

Lewis, Diana M.

2005 Arguing in English and French asynchronous online discussion. Journal of Pragmatics 37(11): 1801-1818. doi: 10.1016/j.pragma.2005.02.014.

Locher, Miriam A.

2004 Power and Politeness in Action: Disagreements in Oral Communication. Berlin/Boston: de Gruyter.

Locher, Miriam A.

2006 Advice Online. Advice-giving in an American Internet Health Column. Amsterdam/Philadelphia: Benjamins.

Locher, Miriam A. and Sage L. Graham

2010 Introduction to Interpersonal Pragmatics. In: Miriam A. Locher and Sage Lambert Graham (eds.), Interpersonal Pragmatics, 1-13. Berlin/Boston: de Gruyter.

Locher, Miriam A. and Richard J. Watts

2005 Politeness theory and relational work. Journal of Politeness Research 1(1): 9-33.

Locher, Miriam A. and Richard J. Watts

2008 Relational work and impoliteness: Negotiating norms of linguistic behaviour. In: Derek Bousfield and Miriam A. Locher (eds.), Impoliteness in Language. Studies on its Interplay with Power in Theory and Practice, 77-99. Berlin/ Boston: de Gruyter.

Lu, Jingyan, Ming Ming Chiu and Nancy WaiYing Law

2011 Collaborative argumentation and justifications: A statistical discourse analysis of online discussions. Computers in Human Behavior 27(2): 946-955. doi: 10.1016/j.chb.2010.11.021.

Luzón, María José

2013 "This is an erroneous argument": Conflict in academic blog discussions. Discourse, Context and Media 2(2): 111-119. doi: 10.1016/j.dcm.2013.04.005. 
Maíz-Arévalo, Carmen

2014 Expressing disagreement in English as a lingua franca: Whose pragmatic rules? Intercultural Pragmatics 11(2): 199-224. doi: 10.1515/ip-2014-0009.

Marcoccia, Michel

2004 On-line polylogues: Conversation structure and participation framework in internet newsgroups. Journal of Pragmatics 36(1): 115-145. doi: 10.1016/ S0378-2166(03)00038-9.

Maricic, Ibolya

2005 Face in Cyberspace: Facework, (Im)Politeness and Conflict in English Discussion Groups. Växjö: Växjö University Press.

Marwick, Alice and Danah Boyd

2011, first published online on July 7, $2010 \quad$ I tweet honestly, I tweet passionately: Twitter users, context collapse, and the imagined audience. New Media and Society 13(1): 114-133. http://nms.sagepub.com/content/early/2010/06/2 2/1461444810365313.

Monteserin, Ariel, Silvia Schiaffino and Analía Amandi

2010 Assisting students with argumentation plans when solving problems in CSCL. Computers and Education 54(2): 416-426. doi: 10.1016/j.compedu.2009. 08.025 .

Mulkay, Michael

1985 Agreement and disagreement in conversations and letters. Text 5: 201-227.

Mulkay, Michael

1986 Conversations and texts. Human Studies 9: 301-321.

Muntigl, Peter and William Turnbull

1998 Conversational structure and facework in arguing. Journal of Pragmatics 29(3): 225-256.

Niemi, Kreeta

2014 "I will send badass viruses." Peer threats and the interplay of pretend frames in a classroom dispute. Journal of Pragmatics 66: 106-121. doi: 10.1016/j.

Ong, Keng Wee pragma.2014.02.012.

2011 Disagreement, confusion, disapproval, turn elicitation and floor holding: Actions as accomplished by ellipsis marks-only turns and blank turns in quasisynchronous chats. Discourse Studies 13(2): 211-234.

Perelmutter, Renee

2010 Impoliteness recycled: Subject ellipsis in Modern Russian complaint discourse. Journal of Pragmatics 42(12): 3214-3231. doi: 10.1016/j. pragma.2010.07.005.

Peters, Brad and Diana Swanson

2004 Queering the conflicts: What LGBT students can teach us in the classroom and online. Computers and Composition 21(3): 295-313. doi: 10.1016/j.compcom.2004.05.004.

Pomerantz, Anita

1984 Agreeing and disagreeing with assessments: some features of preferred/ dispreferred turn shapes. In: J. Maxwell Atkinson and John Heritage (eds.), Structures of Social Action, 57-101. Cambridge: Cambridge University Press. 
Reid, Elizatbeth

1999 Hierarchy and power. Social control in cyberspace. In: Marc A. Smith and Peter Kollock (eds.), Communities in Cyberspace, 107-133. London: Routledge.

Reid, Fraser J. M. and Rachael Hards

1998 The effects of time scarcity on conflict and compromise in computer conferencing. Computers in Human Behavior 14(4): 637-656. doi: 10.1016/s07475632(98)00028-4.

Reynolds, Edward

2011 Enticing a challengeable in arguments: Sequence, epistemics and preference organisation. Pragmatics 21(3): 411-430. doi: 10.1075/prag.21.3.06rey.

Rodino, Michelle

1997 Breaking out of binaries: Reconceptualizing gender and its relationship to language in computer-mediated communication. Journal of Computer-Mediated Communication 3 (3). http://jcmc.indiana.edu/vol3/issue3/rodino.html.

Roschelle, Jeremy, Ken Rafanan, Ruchi Bhanot, Gucci Estrella, Bill Penuel, Miguel Nussbaum and Susana Claro

2010 Scaffolding group explanation and feedback with handheld technology: Impact on students' mathematics learning. Educational Technology Research

Savicki, Victor and Development 58(4): 399-419. doi: 10.1007/s11423-009-9142-9.

1996 Gender language style and group composition in internet discussion groups. Journal of Computer-Mediated Communication 2(3). http://jcmc.indiana.edu/ vol2/issue3/savicki.html.

Schiffrin, Deborah

1984 Jewish Argument as Sociability. Language in Society 13: 311-335.

Schneider, Stefan

2010 Mitigation. In: Miriam A. Locher and Sage L. Graham (eds.), Interpersonal Pragmatics, 253-269. Berlin/Boston: de Gruyter.

Shum, Winnie and Cynthia Lee

2013 (Im)politeness and disagreement in two Hong Kong Internet discussion forums. Journal of Pragmatics 50(1): 52-83. doi: 10.1016/j.pragma.2013.01.010.

Spencer-Oatey, Helen

2000 Rapport management: A framework for analysis. In: Helen Spencer-Oatey (ed.), Culturally Speaking: Managing Rapport through Talk across Cultures, 11-46. London: Continuum.

Sproull, Lee and Sara Kiesler

1986 Reducing social context cues: Electronic mail in organizational communication. Management Science 32(11): 1492-1512.

Tannen, Deborah

1981 New York Jewish conversational style. International Journal of the Sociology of Language 30: 133-149.

Tannen, Deborah

1993 What's in a frame?: Surface evidence for underlying expectations. In: Deborah Tannen (ed.), Framing in Discourse, 14-56. Oxford: Oxford University Press.

Tanskanen, Sanna-Kaisa and Johanna Karhukorpi

2008 Concessive repair and negotiation of affiliation in e-mail discourse. Journal of Pragmatics 40(9): 1587-1600. 
Turnage, Anna

2007 Email flaming behaviours and organizational conflict. Journal of Computer-Mediated Communication 13(1): article 3. http://jcmc.indiana.edu/vol13/ issue 1/turnage.html.

Vandergriff, Ilona

2013 Emotive communication online: A contextual analysis of computer-mediated communication (CMC) cues. Journal of Pragmatics 51: 1-12. doi: 10.1016/j. pragma.2013.02.008.

Vercellone-Smith, Pamela, Kathryn Jablokow and Curtis Friedel

2012 Characterizing communication networks in a web-based classroom: Cognitive styles and linguistic behavior of self-organizing groups in online discussions. Computers and Education 59(2): 222-235. doi: 10.1016/j.compedu. 2012.01.006.

Vraga, Emily K., Kjerstin Thorson, Neta Kligler-Vilenchik and Emily Gee

2015 How individual sensitivities to disagreement shape youth political expression on Facebook. Computers in Human Behavior 45: 281-289. doi: 10.1016/j. chb.2014.12.025.

Weber, H. L.

2011 Missed cues: How disputes can socialize virtual newcomers. Language@ Internet 8. http://www.languageatinternet.org/articles/2011/Weber.

Yus, Francisco

2011 Cyberpragmatics: Internet-mediated Communication in Context. Amsterdam/ Philadelphia: Benjamins.

Zappavigna, Michele

2012 Discourse of Twitter and Social Media: How We Use Language to Create Affiliation on the Web. London: Continuum.

Zhang, Wei and Cheris Kramarae

2014 "SlutWalk" on connected screens: Multiple framings of a social media discussion. Journal of Pragmatics 73: 66-81. doi:10.1016/j.pragma.2014.07.008. 